\title{
Medievalista
}

Online

31 | 2022

Número 31

\section{Carta Por se assim é... breves notas}

Letter Por se assim é... short notes

\section{Maria José Mexia}

\section{(2) OpenEdition}

\section{Journals}

Edição electrónica

URL: https://journals.openedition.org/medievalista/5214

ISSN: 1646-740X

\section{Editora}

Instituto de Estudos Medievais - FCSH-UNL

\section{Refêrencia eletrónica}

Maria José Mexia, «Carta Por se assim é... breves notas», Medievalista [Online], 31 | 2022, posto online no dia 01 janeiro 2022, consultado o 02 fevereiro 2022. URL: http://journals.openedition.org/ medievalista/5214

Este documento foi criado de forma automática no dia 2 fevereiro 2022.

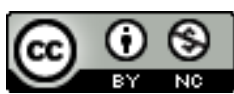

Mediavalista está licenciado com uma Licença Creative Commons - Atribuição-NãoComercial 4.0 Internacional 


\title{
Carta Por se assim é... breves notas
}

\author{
Letter Por se assim é... short notes
}

Maria José Mexia

\section{NOTA DO EDITOR}

Data recepção do artigo / Received for publication: 5 de Março de 2021

1 No reinado de D. Afonso V, vários momentos históricos reflectiram-se directamente em campos tão inesperados como a diplomática régia e o funcionamento de alguns domínios da administração, nomeadamente no Desembargo e na Chancelaria. Os momentos são expressamente mencionados nos documentos: "perdoança jeerall per nos fecta por Refromar despoboaçam de nossas terras" 1 , batalha de Alfarrobeira, tomada de Arzila. A tipologia documental dominante na chancelaria é o perdão ${ }^{2}$ o perdão é uma acção de graça em matéria de justiça. Não apaga um acto punível, como a amnistia, antes anula a penalização. A matéria de graça, por definição, reservada ao rei no seu acto inicial, que pode ser a dada de ofícios, de restituição de fama, de levantamento parcial de tempo de degredo, de legitimação e outros -, uma vez atribuída, passava a obedecer à lei, passava a ser inteiramente tratada como matéria de justiça, isto é, cessava a possibilidade de se aplicar qualquer discricionariedade e consequentemente garantiam-se os direitos e legítimas expectativas de terceiros. É o que está espelhado no texto de uma legitimação feita por D. Duarte: "por ela não seja feito prejuízo a alguns herdeiros lídimos se os aí há, ou a quaisquer pessoas que algum direito hajam nas ditas coisas"'. Preocupação semelhante é a de D. Afonso V quando, em 1454, manda que Gomes Eanes de Zurara substitua Fernão Lopes, que fora escrivão da puridade do Infante D. Fernando, e "guardador de nossas esprituras do tombo que estam no castelo" porque estava "velho e flaco", o qual "huse do dicto ofiçio e guarde a nos nosso serujço e ao pouoo seu direito".

Os desembargadores do Paço eram dois, e as Ordenações referem, minuciosamente, as respectivas funções e jurisdições. Nos casos referentes a acções de graça eles instruíam o processo: uma vez que a decisão pertencia ao rei, era indiferente a posição deles, mas 
quando se tratava de agravos ou apelações, ou seja, acções de justiça em que fatalmente tinha que haver uma maioria a ditar a sentença dos desembargadores, e sendo eles só dois, cada um podia ter seu entendimento, e então recorria-se a mais outro desembargador, o terceiro, que assegurasse sempre essa maioria, e por isso se chamava o terceiro dos agravos 5 .

Os actos eram da exclusiva competência dos desembargadores do Paço, e as respectivas atribuições destes magistrados encontram-se minuciosamente descritas, num total de 29 artigos, minúcia de que é exemplo o artigo $\mathrm{n}^{\circ} 6$ :

“...Os Escripvães (do Desembargo) teraõ esta maneira. Viram as partes a elles e darlhes-ham as petições, e como a parte lha der, o escripvaõ a veja loguo; e se for de feito que peçaõ perdom, a saber, de feridas, paancadas, roubos, força de molher, o Escripvaõ pergunte á parte que a há de dar quanto he aas feridas e paancadas, se forom dadas em reixa, se de propósito, e assi o declare na petiçom, e o tempo em que forom dadas, e se nom trouver estromento de contentamento da parte querellosa, em todo caso diga-lhe o Escripvaõ que vaa por elle e nom ponha a petiçom em roll ataa que o tragua, e quando o trouver faça-lhe o Escripvaõ pergunta se deu já outra petiçom como aquella, e quantas vezes, e que desembarguo ouve della cada vez que a deu, e assi o ponha no roll, e estas perguntas se façam em todollos casos suso scriptos".

O mesmo pormenor se diga dos restantes artigos: no caso de feridas - se for em reixas nova ou de proposito ${ }^{7}$, fogo posto - que fizesse dapno a alguem ${ }^{8}$ - se alguém deixou um preso fugir da cadeia de proposito ${ }^{9}$, restituição de fama ${ }^{10}$, privilégios, legitimações, entre outros, implicando todos eles um longo circuito processual e correspondente meio de obtenção de prova, e com a agravante de que, para obter o perdão régio o suplicante deveria provar que previamente tinha obtido o perdão da parte ofendida ${ }^{11}$.

Cedo se começa a ver, durante a regência de D. Pedro, nos registos de chancelaria ${ }^{12}$, uma pequena alteração na redacção de alguns diplomas no sentido de um certo facilitismo, de diversidade de critérios e de certa arbitrariedade provavelmente devido à "presença" de alguma persona grata que explicaria o privilégio da dispensa de apresentação de provas. Mais ainda: nas acções de graça, as provas que o requerente não apresentava - como devia - eram por vezes mandadas fazer pela coroa, sugerindo que a falta de rigor da instrução dos processos se deveria não só à falta dos requerentes, mas também à necessidade de abreviar o processo burocrático, que facilmente podia não só chegar mas ultrapassar largamente a dezena de itens.

Em 1441 Fernão Vasques, culpado do crime de morte, pede perdão ao abrigo do perdão geral, e é o rei que manda inquirir se em Torres Vedras, terra do morto, vivia algum parente cujo perdão o réu tinha que obter. Depois disso o rei perdoa-lhe, mandando que ficassem acautelados os direitos de eventuais parentes, e quando se refere ao delito em causa, introduz uma pequena reserva: "se não foi de propósito"13. Afonso Gonçalves, no mesmo ano, pede aposentação invocando que está doente de uma perna, e é atendido, mesmo sem apresentar comprovação do que afirma e sem ter idade para tal - privilégio devido provavelmente ao facto de ser membro da casa do conde de Vila Real ${ }^{14}$.

Por outro lado, um pouco mais tarde, em 1453, Rodrigo Afonso, culpado da morte de um homem, foi perdoado pela "perdoança geral" por ocasião da "guerra que tivemos com o Ifante D. Pedro". Foi feita a inquirição devassa que provou que a morte tinha sido sem culpa do suplicante, e apresentada a escritura em que o primo do morto declara que não o quis acusar, pede perdão se tivera alguma culpa na dita morte, acrescentando que tinha servido na guerra na companhia de Gonçalo Teixeira, meirinho do Conde de 
Marialva. Apesar de o suplicante apresentar documentação que prova abundantemente a sua inocência, ainda assim os desembargadores formulam uma reserva - "que lhe perdoassemos algũua culpa se em a dita morte tinha" ${ }^{15}$. Outro fugitivo obtém perdão, e aparece na dispositio uma formulação em substituição da anterior reserva: "se assi he" ${ }^{16}$.

O ano de 1462 é particularmente elucidativo do deficiente funcionamento dos serviços. Basta ver os registos respeitantes à nomeação de tabeliães em que o incumprimento das regras atinge um grau impensável: inúmeras vezes a chancelaria faz apenas o registo do ofício e também acontece que o registo esteja numa folha ${ }^{17} \mathrm{e}$ o termo autógrafo de aceitação do tabelião e o sinal em folha diferente ${ }^{18}$.

9 Fernão Lopes, em 1471, estando preso, inscrevera-se no livro dos homiziados e foi servir na tomada de Arzila, e visto o perdão das partes, de que apresenta escritura pública, e o perdão geral pela dita tomada, e, apesar disso, "se assim é como diz e mais não há", é perdoado ${ }^{19}$. Decididamente, alguma coisa se passava para explicar a ocorrência de tanta falta de rigor - as provas apresentadas pecavam ora por exíguas ora por redundantes. É que tanto o Desembargo como a Chancelaria, instituições-pilares da Coroa, sabiam que corriam o risco de falhar, e a reserva constituía como uma segunda natureza, uma medida de segurança, tão interiorizada estava a dimensão do problema: as duas, estavam, na época, subdimensionadas e impunha-se a solução oferecida - um diploma assumidamente provisório, condicional - é disso que se trata quando se fala em carta por se assimé.

10 Algumas doações de matéria de graça, particularmente os ofícios supostamente vagos por perdas imputadas aos seus proprietários, têm, à margem, um pequeno sumário do qual consta o nome do beneficiado, inúmeras vezes acrescentado pela referida expressão. Porém, não encontramos nas Ordenações Afonsinas, então vigentes, nenhuma referência a esta tipologia, introduzida nas Manuelinas ${ }^{20}$, precedida de umas palavras como de apresentação, de algo novo (tanto que precisa de apresentação).

11 Não é verdade que, no século XVI, fosse algo de inteiramente novo: quando se lê a chancelaria régia de D. Afonso V e de D. João II e a seguir se consultam as Manuelinas tem-se a impressão de que a prática até então vigente é que "é apresentada" à codificação. Na verdade, o que acontece é que à prática anterior havia sido introduzida uma etapa nova, relacionada com os prazos.

12 Certamente depois de um perdão geral era de esperar muita movimentação, muitos requerimentos, muito trabalho administrativo. Certamente depois de Alfarrobeira o volume de trabalho não seria menor: nesse tempo foram muitas as solidariedades quebradas, os bens da coroa que, por confisco, mudaram de mãos, muitos os oficiais que tiveram que se defender da acusação de erros praticados - alegadamente ou não - para não ficarem sem os seus ofícios, muitos os perdões requeridos, sendo que todos estes actos tinham que ser sustentados por escrituras públicas ${ }^{21}$. Tinham, mas nem sempre sucedeu assim. E essas doações, muitas delas estão classificadas justamente como cartas dadas segundo um certo modelo diplomático novo, novo para responder às circunstâncias novas, novo porque ele se impôs. Assim, a carta dada por se assim é, reveste-se de duas características: a) é uma carta de doação de alguma matéria de graça, (qualquer matéria de graça - entre elas o perdão), b) é uma carta que obedece a um modelo especial: a prova documental dos pressupostos invocados como os necessários e suficientes para merecer o acto régio pode não ser apresentada, ao mesmo tempo que compromete insistentemente a palavra dada pelo requerente, e por 
consequência um hipotético diferente apuramento futuro dos factos invocados anula inteiramente a carta.

13 A narratio faz-se eco dos termos que o requerente aduz, o Desembargo acata, aceitando como boas as informações prestadas pelo impetrante, e concede-lhe a graça pedida, mas com uma novidade, introduzida na dispositio: aquele tribunal prescinde da apresentação de prova ou provas $^{22}$, age na base da confiança - se assim é. -, porque não pode em tempo útil responder às solicitações. A todo o tempo, porém, era possível verificar situações ilegais. E corrigi-las ${ }^{23}$. Mais tarde será estabelecido o procedimento devido, incluindo prazos a observar ${ }^{24}$. Já no caso de se tratar de matéria de guerra, consciência ou outra que não de graça, qualquer suspeição de que o serventuário do ofício fosse alvo, seria suficiente para lhe ser retirado o cargo sem mais ${ }^{25}$. Mas não basta que haja verdade naquilo que o impetrante relata - o Desembargo vai muito mais longe: quer a verdade toda, e daí a segunda parte da expressão - e se mais não há.

Esta novidade introduzida no Desembargo no reinado de D. Afonso $V$ reflecte a estratégia adoptada por um serviço sem capacidade para responder eficazmente às solicitações. Sinal de litigância de grandes proporções. E de um correspondente acréscimo de trabalho no despacho dos processos.

Não é de estranhar depois de Alfarrobeira: direi que nem depois nem antes. Pois como interpretar, por exemplo, as queixas unânimes e antigas dos povos em cortes sobre as arbitrariedades praticadas pelos senhorios - todos em geral - acerca dos forais?

Mas se Alfarrobeira explica muita litigância, antes o perdão geral foi motivo de grande movimentação, e o mesmo se diga relativamente à tomada de Arzila ${ }^{26}$, sendo muito diferentes os dois últimos momentos. Um acontecimento jubiloso, como o de 1471, é motivo para festejar com favorecimentos, com actos de indulgência, de graça, um acontecimento em que na população portuguesa não se contavam "derrotados". As cartas pedidas por se assim é aumentam a partir de 1449, em que houve vencedores e vencidos, quando a muitas mercês feitas corresponderam umas tantas tentativas de confisco prévias, em que houve especial necessidade de prover para que os actos de mercê régia não conflituassem nem se traduzissem em actos de injustiça ${ }^{27}$.

$17 \mathrm{Na}$ verdade, alguns vencedores, julgando-se impunes, tentaram cometer arbitrariedades, e esse comportamento teria pesado na adopção desta tipologia diplomática. Seja como for: a verdade é que neste tempo a acção governativa implicou um volume de trabalho para o qual os serviços não estavam minimamente dimensionados.

18 As circunstâncias de ordem prática e logísticas levaram a que fosse sentida a necessidade de se encontrar uma solução que permitisse encurtar e ultrapassar a demora própria da litigância ${ }^{28}$. A premência dos prazos e prejuízos decorrentes do respectivo incumprimento "forçou" a adopção dessa tipologia documental pelo Tribunal. Já que não era possível agilizar o processo jurídico, os termos em que foi criada a carta de se assim é respondiam perfeitamente a tudo quanto era exigível simultaneamente para as matérias de graça e de justiça. A nação entretanto alargava as suas fronteiras e mal "cabia" em si. Houve que inovar - assumindo o Desembargo o carácter provisório, condicional das cartas dadas por se assi é. Se havia alguma certeza era a completa impossibilidade de os serviços herdados de tempos anteriores terem capacidade de responderem ao volume de trabalho, e a solução foi a que a realidade impôs: na altura, não se altera a lei, mas, com lucidez, pressiona-se a população a honrar a palavra dada. Afinal em última análise era sempre possível fazer prova do que 
quer que fosse, até de eventuais declarações falsas. A justiça talvez pudesse esperar, mas não podia falhar.

\section{ANEXOS}

\section{Documento 1}

Paio Rodrigues, confirmação de aforamento

Dom João cet. «Fazemos saber que a Nós disseram que Lopo Gomes Pestana, escudeiro morador em a nossa cidade de Évora, traz duas boticas que são em a dita cidade, no cabo da Rua da Selaria, junto com a praça onde lavram os ourívises, aforadas em fatiota por certo foro em cada um ano e que não tem o dito aforamento nossa confirmação segundo direito e nossa ordenança, pela qual cousa ele perde o dito aforamento e lhas podemos tirar e dar a quem nossa mercê for. E ora, querendo Nós fazer graça e mercê a Pai Rodrigues cavaleiro de nossa Casa, seu genro, se assi é que as ele perca pelo que dito é, ou per qualquer outra maneira que seja... Temos por bem e fazemos-lhe dela[s] mercê per aquele foro e maneira que as o dito Lopo Gomes de Nós traz e esto assi e per a guisa que as o dito Pai Rodrigues até qui foi per carta de se assi é del rei meu senhor e padre... E porém mandamos ao nosso contador cet., que sendo citado e ouvido cet. senão no cabo onde se a nota dela acaba porão Com tal condição que tanto que em posse delas for, venha tirar sua carta de aforamento e confirmação, segundo nossa ordenança cet». Dada em... «El rei o mandou per Martim Vaz cet., vedor da Fazenda. Gaspar Luís a fez». (L. N.: Odiana $)^{29}$

\section{Documento 2}

Quanto tempo duram as Cartas impetradas por se assi he. E do que ouue perdam depois de as ditas Cartas serem impetradas

Porquanto muitas pessoas impetram de nós ou de nossos oficiais que para elo nosso poder têm, cartas de dadas de ofícios ou de alguma fazenda ou outras coisas por se assi he, e depois de as terem se leixam estar sem citarem nem demandarem as partes contrárias de que se seguem muitos inconvenientes, ordenamos que quando alguma pessoa impetrar tal carta por se assi he, cite a outra parte contrária dentro de seis meses do dia que a dita carta for feita, e não o começando a demandar dentro do dito tempo, não poderá jamais pela dita carta demandar seu adversário em tempo algum, e a dita dada e mercê que lhe assi era feita pela dita carta será de nenhum efeito. E posto que nesse tempo dos seis meses a parte contrária haja nosso perdão, não prejudicará à parte que já tinha nossa carta passada pela chancelaria ${ }^{30}$.

Documento 3

Alvara pera sobre (sic) os ofíçios que se pedem por se asy he

Nos el Rey fazemos saber a vos vedores de nosa fazenda que avendo nos Respeito como as pesoas que te quy pidiam os ofícios per eros aquelles que os de nos tinham nom pagavam deles outra cousa saluo a chamcelaria ordenada era azoo de lhe darem fadiga 
e trabalho quando lhe nom provam os ditos eros e querendo a ello prover como nos parecer bem e nosso seruiço ordenamos ora que daquy em diante toda pesoa que pidir quallquer ofiçio que seja per eros e lhe for outorgado per nos ou per quem nosso poder ou autoridade teuer pera yso pagem do dito oficio a metade do preço e comthia que pagaria se lhe fose dado per vaga e sendo a parte condenada per semtença finall em perdimento do dito oficio ou que nom queira apelar nem agravar queremos que alem de o perder page de pena o preço jmteiro em que o dito oficio estever avaliado, scillicet, a metade per aquelles lho pidio e a tever paga em nosa chamcelaria e a outra metade se arrecadara pera nos porque fazemdo o semelhamte oficiall taees eros per que o deva perder he rezam e Justiça que nam somemte o perqua maas ajmda que page a dita penna de dinheiro e posto que a parte que o tall ooficio pidir aja dele a dita semtença nom sera metido em pose dele te primeiro aver diso nosso despacho de como pagou e nas cartas que pasarem dos semelhamtes ofiçios jra loguo posta e decrarada a dita crausola e pera mays brevidade da parte e aver majs asinha a pose do dito oficio as justiças da terra a que esto//18v// pertemçer fara fazer enxuqueçcam nos beens dos comdanados per que se aja o preço do dito oficio que a de ser o dobro do que se pagou pla carta quando dito oficio deremos e a metade delle façam emviar a nosa corte e aver diso a dita provisam e a outra metade se dará a dita parte Porem vos mamdamos a vos e asy ao nosso chamcharell moor espriuam da poridade e pesoas outras a que esto pertençer que hasy o cumpraes e guardees e façaees comprir e guardar como aquy he comteudo e este aluara far se a asentar no liuro dos Regimentos de nosa fazenda feito em almeirjm aos ix dias do mees de Novembro Antonio de Neiua o fez anno de mjll $b^{c}$ xbij3.

\section{NOTAS}

1. Lisboa, Torre do Tombo, Chancelaria de D. Afonso V, lv. 2, fol. 45v, $3^{\circ}$ doc. Santarém, 16 de Dezembro de 1441.

2. $\mathrm{O}$ mesmo se diga relativamente à chancelaria de D. João II em que os perdões são mais de metade do total de diplomas.

3. Lisboa, Torre do Tombo, Chancelaria de D. Duarte, lv. 1, fol. 60v. Legitimação a Gonçalo Anes.

4. Lisboa, Torre do Tombo, Chancelaria de D. Afonso V, lv. 10, fol.30, no 4 .

5. Lisboa, Torre do Tombo, Ordenações do rei D. Afonso V, lv. I, 4.

6. Lisboa, Torre do Tombo, Ordenações do rei D. Afonso V, lv. I, título IV, \& 6.

7. Lisboa, Torre do Tombo, Ordenações do rei D. Afonso V, lv. I, título IV, \& 7.

8. Lisboa, Torre do Tombo, Ordenações do rei D. Afonso V, lv I, título IV, \& 9.

9. Lisboa, Torre do Tombo, Ordenações do rei D. Afonso V, lv. I, título IV, \& 12.

10. Lisboa, Torre do Tombo, Ordenações do rei D. Afonso V, lv. I, título IV, \& 28.

11. Lisboa, Torre do Tombo, Ordenações do rei D. Afonso V, lv. I, título IV, \& 2 a 6 .

12. Faltam alguns livros do reinado. Os efeitos do terramoto são visíveis em alguns dos códices que chegaram até nós: folhas encadernadas ao contrário, dupla numeração por junção artificial de folhas soltas e cadernos recolhidos no entulho da Torre do castelo.

13. Lisboa, Torre do Tombo, Chancelaria de D. Afonso V, lv. 2, fol. 53, doc. $2^{\circ}$. Santarém, 24 de Novembro de 1441.

14. Lisboa, Torre do Tombo, Chancelaria de D. Afonso V, lv. 2, fol. 53, doc. $3^{\circ}$. Montemor, 28 de Outubro de 1441.

15. Lisboa, Torre do Tombo, Chancelaria de D. Afonso V, lv. 3, fol. 23, doc. 6o. Évora, 2 de Março de 1453. 
16. Lisboa, Torre do Tombo, Chancelaria de D. Afonso V, lv. 10, fol. 30, doc. $4^{\circ}$.

17. Lisboa, Torre do Tombo, Chancelaria de D. Afonso V, lv. 1 , fol. 31 , doc. $4^{\circ}$.

18. Lisboa, Torre do Tombo, Chancelaria de D. Afonso V, lv. 1, fol., $32 \mathrm{v}, 3$. e e último doc., com sinal. Caso extremo: um "registo", sem intitulação, de perdão pela morte de Pedro Afonso, na condição de que o culpado (nunca mencionado) cumpra as condições das partes; sem elemento topográfico, apenas o ano de 1476. Lv. 6, fol., 25, 3ํ doc.

19. Lisboa, Torre do Tombo, Chancelaria de D. Afonso V, lv. 21, fol. 5 , doc. 4 . Lisboa, 5 de Novembro de 1471.

20. Lisboa, Torre do Tombo, Ordenações do rei D. Manuel I, lv. 1, título LXXV.

21. Grande percentagem de cartas de perdão e outras dadas por se assim é refere o nome do tabelião em que a requerida escritura fora feita, informação que importa, visto que se perderam quase todos os livros de notas do século XV - dos tabeliães do público e do judicial de todo o país -, século representado pelo livro da Sé de Lamego, e grande parte dos livros do princípio do século XVI (de que é quase excepção o Livro de notários da Ponta do Sol, 1532-33). Dessa perda não se pode assacar a culpa (ao menos uma vez) apenas ao terramoto.

22. O número de provas que podiam ser pedidas não tem fim: confirmação em caso de fuga, das circunstâncias, inclusivamente se foi acompanhada ou facilitada e por quem, se tirou inquirição de todos os actos referidos, como fora a fuga da prisão, se a porta estava ou não aberta, se o fugitivo se fora inscrever no livro dos homiziados, se pedira mesmo para ir servir fora, se obtivera redução de tempo de degredo ou serviço e onde.

23. Ver documento 1.

24. Lisboa, Torre do Tombo, Ordenações do rei D. Manuel I, lv. I, título LXXV; e Lisboa, Torre do Tombo, Leis e Regimentos, lv. 16, fols. 18-18v., 1517. Ver docs. n.. 2 e 3.

25. Os ofícios de justiça ou fazenda de que houver notícia de que não são bem servidos, ser-lhesão tirados mesmo quando "nam haa prouas tam claras, porem haa quanto abasta para sermos certo sermos delles mal seruido e fazerem mal seus officios e errarem nelles. (...) os possamos tirar dos sobreditos sem para isso lhe sermos em obrigação alguma". Lisboa, Torre do Tombo, Ordenações do rei D. Manuel I, lv. I, título LXXVI.

26. Lisboa, Torre do Tombo, Chancelaria de D. Afonso V, lv. 21, fol. 5, doc. ํo 4. Perdão a Fernão Lopes, morador em Alcochete, por ter ferido dois homens que ficaram sãos e sem cajão. Andando amorado, inscreveu-se no livro dos homiziados, e foi servir o rei na tomada de Arzila, e obteve perdão das partes, como consta do instrumento respectivo, feito por Bartolomeu Anes, tabelião no dito lugar, datado de 5 de Outubro de 1471. Vendo o que alega e se asy he como ele diz e hi majs nom ha e visto o perdão das partes e o perdão geral, e que o acusado se foi inscrever no livro dos homiziados, o rei perdoa-lhe, em documento passado por Pero da Silveira, do Desembargo do Paço e Petições e pelo desembargador e bacharel em Leis Pero da Costa, e datado de Lisboa, 5 de Novembro de 1471.

27. As $O$. A. datadas de 1446, foram acrescentadas em 27 de Junho de 1449, no Livro V, com o título CXX Dos que forom na Batalha da Alfarrobeira contra serviço de el Rey, e outro, título CXXI, sobre outro assunto.

28. Lembrar a necessidade premente de obviar às dificuldades sentidas no universo da administração geral: expressa na delegação de poderes feita pelo rei na figura dos capitães do Brasil nos anos 30 do século XVI. As Ordenações dizem a abrir o I Livro, Tít. 15, que a criação de capitães na terra e no mar é o primeiro dos direitos reais do rei. De acordo com a doação das capitanias, “o (dito) capitão e governador e todos seus sucessores a quem esta capitania vier possam novamente criar e prover por suas cartas os tabeliães do público e judicial (...) e lhes darão suas cartas assinadas por eles e seladas com o seu selo, e lhes tomarão juramento que sirvam seus ofícios bem e verdadeiramente, e os ditos tabeliães servirão pelas ditas cartas sem mais tirarem outras de minha chancelaria, e quando os ditos ofícios vagarem por morte ou por 
renúncia ou por erros de se assim é, os poderão isso mesmo dar, e lhes darão os regimentos por onde hão-de servir, conformes aos da minha chancelaria, e hei por bem que os ditos tabeliães..." Instalada junto do capitão, de cada capitão, havia naturalmente uma chancelaria, embrionária mas não dispensável, e um arquivo régio, uma Torre do Tombo onde em princípio se esclareciam os erros por se assim é, ou seja, esta tipologia documental era mesmo de importância capital, tanto que forçou a sua entrada nas Ordenações.

29. Lisboa, Torre do Tombo, Chancelaria de D. João II, lv. 6, fol. 78, doc. $2^{\circ}$. Évora, 8 de Junho de 1482. O documento foi-me facultado pela Susana Pedro, a quem agradeço, e faz parte do projecto de leitura integral da chancelaria de D. João II, promovido pela Comissão dos Descobrimentos, levado a cabo por um grupo de trabalho sob a orientação geral do Prof. Borges Nunes.

30. Lisboa, Torre do Tombo, Ordenações do rei D. Manuel I, lv. I, título LXXV.

31. 31 Lisboa, Torre do Tombo, Leis e Ordenações, Leis e Regimentos de D. Manuel, lv. 16, fols. 18-18v.

\section{AUTOR}

\section{MARIA JOSÉ MEXIA}

Ex-Arquivista da Torre do Tombo, Lisboa, Portugal. mjmexia@netcabo.pt 